\title{
Detection of DEHP in Beverages Sold in Canada using Gas Chromatography-Mass Spectrometry
}

Nicole Truong ${ }^{1}$, Vanessa Karakilic ${ }^{2}$, Kevin Soulsbury ${ }^{3}$

1 Lead Author, B. Tech Student, School of Health Sciences, British Columbia Institute of Technology, Burnaby (BCIT), BC.

2 Supervisor, School of Health Sciences, British Columbia Institute of Technology, Burnaby, BC. 3 Supervisor, School of Academic Studies, British Columbia Institute of Technology, Burnaby, BC.

Received 2 May 2016

\section{Abstract:}

Phthalates are a class of plasticizing chemicals used to improve the flexibility of soft plastics $(1,6,12$, 15). As such, they have drawn increased attention as food contact substances $(1,10,14)$, mostly entering food items from packaging materials $(1,8,10,14)$. Even though they had been approved as indirect food additives in Europe and the U.S. (1), the discovery of high concentrations of di(2-ethyl-hexyl) phthalate (DEHP), also known as bis 2-ethylhexyl phthalate (BEHP) $(12,15)$, in a probiotic food product by a scientist from Taiwan in April 2011 initiated the world's greatest health safety efforts (7). Investigators found that DEHP, along with other phthalates, were deliberately added to food products in replacement of the approved food additives, which would normally be added to emulsify the components in the drinks to achieve a natural and appealing appearance $(7,12,15)$. This contamination event has been known as the 2011 Taiwan Food Scandal, where processed food items such as sports drinks, concentrated juice beverages, tea drinks, jam or jelly and food supplements were adulterated with phthalates, a harmful class of chemical compounds. Consequently, ingestion of these harmful compounds may result in adverse health affects such as endocrine disruption, malformation of reproductive organs, infertility and abnormal neurodevelopment (12). Many products made it across the border to 22 different countries $(15,17)$ including Canada and U.S. (17). Since then, the Taiwanese government made improvements to the food industry regulations $(15,17)$. This study was aimed to determine if DEHP was present, and compared to the European Food Safety Authority (EFSA) DEHP tolerable daily intake (TDI) of $0.05 \mathrm{mg} / \mathrm{kg}$ body weight (bw)/day $(12,17)$, in 30 different drinks of imported and domestic brands sold in Canada. For comparison purposes, the author completed calculations based on the average adult (over 18 years old) body weight of $70 \mathrm{~kg}$, according to EFSA (41). Using liquid/liquid extraction followed by Gas Chromatography-Mass Spectrometry (GC-MS), 30 beverages were tested and analyzed for the presence of DEHP. Low concentrations of DEHP was detected in 3 of the beverages and none in the other 27 beverages tested on a calibrated instrument. The concentrations detected for the 3 beverages were lower than the TDI for a $70 \mathrm{~kg}$ body weight. Control samples were used to ensure method validity.

Key words: DEHP, di(2-ethyl-hexyl) phthalate, bis 2-ethylhexyl phthalate (BEHP), imported drinks, imported beverages, Canadian beverages, US beverages, bubble tea, 2011 Taiwan Scandal, phthalates 


\section{Introduction}

In the 2011 Taiwan Food Scandal, the Taiwan Food and Drug Administration (TFDA) reported the illegal use of industrial plasticizers, di(2ethyl-hexyl) phthalate (DEHP) and di-isodecyl phthalate (DINP), as clouding agents by the food industry (15). These plasticizing substances were used in replacement of the approved clouding agents such as palm oil and gum Arabic, food additives that improve the turbidity of the product to appear more natural and appealing (15). At one point, TFDA reported that at least 965 food products (including beverages) were contaminated, of which 206 items had been exported to 22 different countries, including US, England, Canada, Japan, China, Germany, Australia, New Zealand, Brazil, South Africa, Vietnam, Hong Kong and Philippines (15). The contaminated products included foods from five categories: sports drinks, concentrated juice beverages, tea drinks, jam or jelly and food supplements in capsule or powder-form $(14,15$, 17). After the revelation, the Taiwanese government officials were able to trace back to the implicated factories where the contaminated products were produced, recalled the products from the stores and destroyed all of the contaminated goods in a public manner $(7,17)$.

As this contamination scare was not the first, occurring after the 2008 melamine-tainted infant formula in China $(15,17)$, the public, both locally and globally (16), lost confidence (17) in certain food products after the events and responded in worries and confusion (16). For more than a decade, the distribution of phthalatecontaminated food products had gone unnoticed, nationwide in Taiwan, and globally $(16,17)$. This calls for the development of a better regulation and detection system to find out of any contamination occurrence earlier or prevent the illegal use of phthalate.
Since many different chemical forms of phthalates are ubiquitous in the environment, in water, air and food, they have been studied comprehensively by the European Union (13). The findings concluded that phthalates were harmful (13). In general, they have been classified as toxic substances and endocrine disrupters by most countries including the United States and European countries $(1,11,13)$. As phthalates were determined to have detrimental health implications and yet limited research has been done on phthalate contaminated drinks, there would be a public health significance for the author's research project.

This paper will identify the structure of phthalates and their use in the industries and any general health effects that they may impose on humans by their consumption. The author will identify research, policy and knowledge gaps to help attract the attention of the food related agencies and the public to attune to the issues with contaminated foods as a global issue (17).

The purpose of this project is to detect for the presence of one of the phthalate compounds, DEHP, in different brands of beverages sold in Canada to evaluate how many full portions (cans, bottles etc.) of the beverage may be consumed per day before there may be any implications of health risks. This evaluation can be achieved by comparing the detected level of DEHP within the full portion of the drink to the aforementioned TDI for a $70 \mathrm{~kg}$ body weight.

With certain considerations, the methodology chosen for extraction and analysis of DEHP for this project will utilize liquid/liquid extraction and Gas Chromatography-Mass Spectrometry (GC-MS). Due to a limited budget and time, the research project will test for the presence of DEHP in 30 different domestic or imported drinks distributed in Canada and, if detected, 
compare to the tolerable daily intake (TDI) of $0.05 \mathrm{mg} / \mathrm{kg}$ bw/day, established by the European Food Safety Authority (EFSA). Calculations will be completed based on a body weight of $70 \mathrm{~kg}$, the average adult body weight (over 18 years of age) acknowledged by EFSA (41), for comparison purposes. Furthermore, any limitations to the overall methodology will be identified.

\section{The 2011 Taiwan Food Scandal}

The 2011 Taiwan Food Scandal was the first known event in Taiwan that involved deliberate contamination of food items, which included drinks (15). Certain manufacturers were adulterating the drinks with illegal food additives such as DEHP and DINP, harmful substances to human health by consumption (15). The beginning of the revelation of this scandal started when a scientist was testing for contaminants in probiotic supplements and noticed an unusual indication of the presence of a compound in the test $(11,15)$. The compound was detected as, approximately 600ppm, of DEHP $(11,15)$. After further screening of other food products for six phthalates including DEHP, DINP, DIDP (diisodecyl phthalate), DNOP (di(n-octyl)phthalate), DBP (di-n-butyl phthalate), and BBP (butyl benzyl phthalate) (17), surprisingly, many more products such as milk tea, sports drinks, grass jelly drinks, jam and jelly and powder nutraceuticals were found to be tainted with DEHP and/or DINP (15). The story was unfolded after positive tests for phthalates in certain food products gave traceability back to the suppliers of these plasticizers. It was reported that bubble tea pearls, also known as tapioca pearls, also had been tainted with phthalates and other materials $(15,19)$. Following this contamination food scare, officials from Taiwan attempted to improve the image of their food industry by launching the following long-term initiatives: systemic industry and management improvements, risk assessment and prevention in policy support and continuing care and follow-up (15).

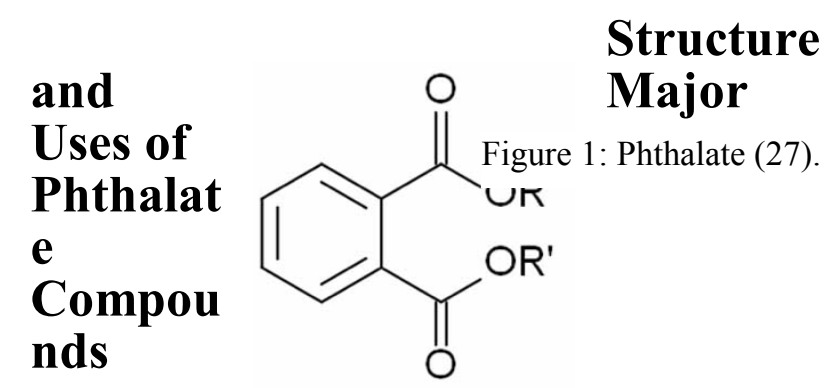

Phthalates are a class of compounds with the general chemical structure seen in Figure 1, where R and R' are alkyl groups, consisting of hydrocarbons.

\footnotetext{
Variations of phthalate Figure 2: DEHP (29). compounds depend on the alkyl groups. This can be exemplified by the structure of DEHP, which consists of two 2ethylhexyl alkyl groups attached to the ester functional groups (Figure 2).
} 
detected in food materials as a result of migration, leakage or evaporation, although in very small concentrations $(1,4,9)$. It was noted that the major routes of exposure to phthalates were oral, dermal, inhalation and intravenous (9).

\section{Health Effects of Phthalates from Human Consumption}

Phthalate compounds are plastic softeners, added to plastics such as polyvinyl chloride (PVC), polyethylene (PE) and poly-vinyl acetates (PVA), to improve their flexibility, extensibility, elasticity and workability $(1,8,17)$. For example, DEHP is a phthalate compound used in toys (27), building products, car products, footwear, raincoats, food packaging, and medical devices and tubing (1). DINP is used in garden hoses, pool liners, flooring tiles and toys (1). DIDP is used in artificial leather, coverings on wires and cables, pool liners, toys and carpet backing (1). DNOP is used in flooring, tarps, garden hoses and pool liners (1). DBP is used in latex adhesives, personal care products, cellulose plastics and dyes (1). BBP is used in vinyl tiles, food conveyor belts automotive trim, artificial leather and traffic cones (1). Other phthalates are used in various other consumer products (1).

\section{Human Exposure to Phthalates}

Phthalates are ubiquitous environmental pollutants due to their widespread use (6), mainly as a plastic softener for consumer products $(1,6)$. Studies have shown that phthalates may be present in drinking water, both in tap and bottled water (6). Because of their widespread use, it is not surprising that they have also been detected as air contaminants as well (5). Since phthalates are not chemically bound to the packaging materials, they have also been
Phthalates have been studied extensively and have been shown to have endocrine disrupting capabilities and reduce fertility in males in animal studies $(9,11)$. Since the development of male structures are dependent on androgens, this process will be disrupted by phthalates as a result of fetal testicular testosterone biosynthesis inhibition (11).

An article written about the food contaminants and their effects on children suggested that the adverse effects in child development and malformations of the reproductive body parts may be attributed to endocrine disruptors, such as phthalates (12). Shortly after the food scandal $\mathrm{a}$

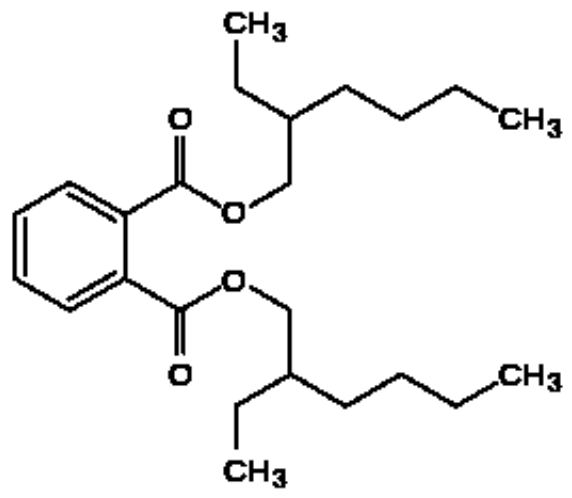
event, study

following 60 children, who consumed phthalates, over a 6-month period showed a reduction in thyroid stimulating-hormone (TSH) (12).

Epidemiological studies have suggested associations between phthalate exposure and adverse health outcomes in infants and children 
such as shorter penis, shorter gestational age, pubertal gynecomastia, premature thelarche, thyroid hormone alteration, incomplete testicular descent as well as low intelligence quotient (11). Other adverse health outcomes include shorter anogenital distance, eczema, sex hormone alteration, precocious puberty, asthma, rhinitis, low birth weight, attention deficit hyperactivity disorder and hypospadias in infants and children (11).

The European Food Safety Authority established TDIs for multiple phthalates. The TDI for DEHP is $0.05 \mathrm{mg} / \mathrm{kg}$ body weight (bw)/day, and DINP and DIDP is $0.15 \mathrm{mg} / \mathrm{kg}$ bw/day $(12,17)$.

\section{Strengths and Limitations of the Literature Review}

As an occasional consumer of bubble tea, the author was initially curious on whether the bubble tea served in Canada would be tainted with any amount of phthalates as she became aware the 2011 Taiwan Food Scandal event (19). Unfortunately, there were not many research articles on this topic. The author suspects that the few results may be a result of the literature search being in English instead of in Taiwanese. Certain articles mentioned that Taiwanese officials had taken research initiatives in the matter of phthalates, their detection and health effects (15); hence, the author believed that a greater extent of research has been done in Taiwan on phthalates and bubble tea.

\section{Regulations for Imported Food}

The regulations on the implicated imported foods, such as fruit drinks and other processed drinks and nutraceuticals, that may contain phthalates may fit under the categories of sports nutrition products and processed fruit and vegetable products on the Canadian Food Inspection Agency website (CFIA) (18). The imported products must meet requirements of labeling under the Processed Products Regulations under the Canada Agricultural Products Act (20) and Food and Drug Regulations (21). Labels should accurately indicate all of the components in the product. These items are subject to inspection by the Canadian Food Inspection Agency personnel (18).

\section{Gaps in Legislation}

Although scientists found phthalates in food products and action was taken by authorities to eliminate these products (15), it may still be difficult to change the manufacturers' behaviour for the future. With strict requirements for imported goods in Canada and the US such as labelling $(20,21)$, it may still be difficult to monitor for every type of chemical that may be present in food. In Canada, analytical tests of imported goods are being completed on an annual basis (38); however, these tests are being tailored to different information and risks gathered each year (38). This is because there are numerous chemicals that exists and it would not be realistic to test for all of them in every imported product. Food adulteration may go unnoticed, unless an event occurs, such as an illness, that may call for an investigation to be done and a trace-back of all food events may lead to the implicated food product. Only then would analytical tests be completed to verify that certain food products may or may not be adulterated (38). When an event with food contamination occurs, it is hard to trace back to the real source of contamination $(15,17)$. It is even harder to trace back to the time the deliberate or non-deliberate contamination event occurs and how long the public have been 
consuming the tainted products for $(15,17)$. Having checks at the border between countries is just a preventative measure but there is no guarantee that another food scandal could not happen again and be detected early.

\section{Future Needs and Recommendations}

As the government in developing countries are making rapid economic growth as their first priority, they often compromise environmental safety and public health (17). Taiwan needs to continue fostering their long-term strategies in protecting the public from the food industry's hidden agenda $(15,16)$. As the literature has revealed, after the food scandal event in 2011, Taiwan officials have mobilized laboratories to test for levels of phthalates and other contaminants in certain food products and developed tolerable daily intake (TDI) levels for five different phthalates $(15,17)$. They have also destroyed the tainted products and prohibited export of the products $(15,17)$. Methods to track levels of phthalates in patients have been developed and followed (15). A website was created to offer information to the citizens in Taiwan and other countries at risk (15). At this point, it is unknown to the author what the website URL is and which countries it is offered to. Improved communication via educational tools to the public have been initiated (15). Punishment has been imposed on those who violate the food safety policies (15). Although with these preventative measures in place, it is best to keep in mind that it is very likely that adulterated food occurrences will happen again as this food scandal is not the first. In order to prevent occurrences of deliberate food contamination like this from happening, there must be an education system that promotes knowledge, attitude and action (16) in developing countries such as Taiwan since these products are sold to other countries. Previous research indicated that there is a gap in knowledge of consumers on the food products and the risks, especially Taiwan college students according to a study completed (16). The literature suggests for improvements in the country's responsibility in the international trade with regards to food safety, the producers' and processors' obligation to ensure food safety and quality, food safety law and effective traceability system (16). The gap in legislation of imported goods between Taiwan and North America is that even with the stringent legislation on labelling on the imported products, the presence of this trade is developed on mere trust that is based in the honesty of the food industry. These checks could easily fail if honesty is not in other countries' best interest.

\section{Methodology}

30 different beverages of imported or domestic drinks from various brands were collected from vendors in different cities including Richmond, Burnaby, Vancouver, Surrey and Langley in British Columbia, Canada. The vendors were selected at random by generating a list on google map and randomly selected by the author to produce a sample size of drinks from various countries and with various contents. Samples were kept refrigerated after purchase for consistency. The cans were rinsed with distilled water to wash away impurities on the cans before opening. Gloves were used to handle the apparatus and materials to prevent contamination. The null hypothesis and alternate hypothesis (Ho and $\mathrm{Ha}$ ) were established for each drink as follows:

Ho $=$ The level of DEHP detected in one full portion of the beverage is less than or equal to the TDI of $0.05 \mathrm{mg} / \mathrm{kg}$ bw/day for a $70 \mathrm{~kg}$ body weight. 
$\mathrm{Ha}=$ The level of DEHP detected in one full portion of the beverage is greater than the TDI of $0.05 \mathrm{mg} / \mathrm{kg} \mathrm{bw} /$ day for a $70 \mathrm{~kg}$ body weight.

The analytical method involved preparation of the samples to be analyzed by a calibrated GCMS instrumentation (22). This method is typically used and proven to screen several different phthalates in contaminated beverages (28). However, it is not the only method available (28). The description of the sample preparation procedure is provided below for the beverage sample, the standard control sample, the blank control sample and the spiked sample.

\section{Sample Preparation Procedure:}

\section{Beverage samples:}

$1 \mathrm{~mL}$ of the beverage sample was pipetted into the plastic test tube. $5 \mathrm{~mL}$ of $1 \mathrm{M}$ acetic acid was pipetted into the same plastic test tube. The test tube was capped and swirled to mix for 2 minutes and placed into the centrifuge equipment for 5 minutes. Cloudy solutions warranted the connection of the 0.45 um nylon filter media to the syringe, then the 0.20 um nylon filter media to the 0.45 um nylon filter media. This allows for larger particles to be filtered out first to improve the efficiency of the filtering process. Clear solutions warranted the connection of only the 0.20 um nylon filter media to the syringe. (Note: these devices are made to connect the output to the input ends). The glass vial was placed at the output end of the last nylon filter media (the 0.20 um). The plunger was removed from the syringe, into which the solution was poured from the test tube. The plunger was used to push the solution in the syringe through the filter media into the small glass vial until two thirds full. The vial was capped with a lid. This sample was ready for the analytical procedure. A duplicate sample was made by repeating the steps.

Standard Control samples:
These samples were prepared by diluting 5000 ppm DEHP standard (23) to $50 \mathrm{ppm}$ with $1 \mathrm{M}$ acetic acid. This was accomplished by adding $0.100 \mathrm{~mL}$ of the DEHP standard into a $10 \mathrm{~mL}$ flask and topping it up with $1 \mathrm{M}$ acetic acid to the mark. Only one standard control sample was required to be analyzed with each batch of beverage samples analyzed. These samples were used as a quality control of known concentration of DEHP to confirm that the entire analytical system during each batch of samples prepared and analyzed and eliminate bias from analytical results (26).

\section{Blank Control samples:}

These samples (also known as the method blanks) were prepared in the same manner as the beverage samples using distilled water instead of the beverage sample. This sample was used as a control sample to account for any possible DEHP contamination from sources from the analytical system (26). DEHP should not be detected in this sample if no contamination occurred from other sources. If DEHP is detected in this sample, then, it can be inferred that it came from the analytical system and a closer investigation shall ensue. Only one method blank was analyzed with each batch of beverage samples analyzed.

\section{Spiked samples:}

These were prepared by adding $0.100 \mathrm{~mL}$ of the $5000 \mathrm{ppm}$ standard DEHP solution into a $10 \mathrm{~mL}$ volumetric flask and topping it with the beverage sample to the mark. Next, this solution went through the beverage sample preparation procedure in replace of the beverage sample. Spiked samples were used to calculate the signal strength difference between the beverage sample and spiked sample to deduce the concentration of the DEHP in the original beverage sample. It was also used as a control sample to ensure DEHP was detected. 
Batches of samples collected on the same day were analyzed together on the GC-MS instrument. In addition, one control standard and one method blank were analyzed with each batch of samples. The control standard and method blank were control samples used to ensure that the method can identify for DEHP and sources of DEHP that were not part of the beverage respectively. The analytical procedure is outlined below.

\section{Analytical Procedure:}

(This part of the procedure was completed by the Kevin Soulsbury, BCIT Chemistry professor)

The glass vials of the batches of prepared samples were placed into the GC-MS instrument for analysis. Samples were analyzed in both normal and sensitive settings. The normal settings allowed for detection of all ions in general whereas the sensitive settings allowed for specific detection of the ions of interest. DEHP was identified via a set of peaks in the spectrum, produced by the GC-MS instrument, that were consistent with the compound (which was identified through pilot studies using control samples containing DEHP). Each peak corresponds to a specific ion of the precursor DEHP compound that can be identified by a number. The ion that distinguishes DEHP from other compounds can be identified by peak \#149.

\section{Results}

After analyzing 28 different drinks, only beverage \#28 showed detection for DEHP (Appendix Table 1). As expected, all of the method blanks that were prepared with each batch of samples analyzed showed no detection of DEHP while the control standard samples analyzed along with each batch of samples indicated a large signal for DEHP. These control samples confirmed the validity of the method.

Because beverage \#28 showed positive results, two other beverages were randomly selected for re-analysis along with \#28, beverage \#14 and \#18, for replicability purposes (Appendix Table 2). A beverage sample and a spiked sample was prepared for both sample \#14 and \#18. As expected, DEHP was not detected in the beverage samples but was detected in the spiked samples for samples \#14 and \#18 (Appendix Table 2). Multiple replicates of beverage samples and one spiked sample were prepared for beverage \#28 (Appendix Table 2). Surprisingly, the beverage samples showed detection of DEHP but the spiked sample did not for beverage \#28. It was unclear why the spiked sample for beverage \#28 was not detecting DEHP (Appendix Table 2). By observation, during the sample preparation procedure, beverage \#28 showed small clumps after the addition of DEHP into the sample.

At this point, a slight change in procedure was made by using $1 \mathrm{~mL}$ of the beverage and $1 \mathrm{~mL}$ of acetic acid instead of $5 \mathrm{~mL}$ acetic acid to achieve a lower dilution. Replicates for beverage \#28 with one spiked sample were prepared using this new procedure. Results continued to be inconsistent with expectations for beverage \#28 (Appendix Table 3).

Another slight change in procedure was made to using methanol instead of acetic acid, using the 1:1 ratio of the beverage and methanol this time. Two beverage samples and two spiked samples were prepared for beverage \#28 using this new procedure. Consistent results were achieved with this change for sample \#28 (Appendix Table 4).

The same method was then used to prepare a set of duplicate beverage samples for \#29 and \#30, 
for a trial analysis. Beverage \#29 showed no detection of DEHP while beverage \#30 showed detection of DEHP for both replicates. Since beverage \#30 was detected for DEHP, the method was repeated to include two beverage samples and two spiked samples for \#30 (Appendix Table 5). Results indicated that DEHP was present for both the beverage samples and the spiked samples (Appendix Table 5).

However, due to the time and funding constraint, the rest of the beverages \#1 to \#27 could not be re-analyzed with the new method. There was time to re-analyze only one more randomly selected beverage, \#11, using the new method. Results indicated that DEHP was present in beverage samples and the spiked samples of beverage \#11 (Appendix Table 5).

As a result, there were only four beverages that were analyzed following the new method, beverage \#11,\#28, \#29 and \#30. Appendix Table 6 shows a summary of the overall results for DEHP detection for the new method using methanol instead of acetic acid.

Overall, there were only three beverages that were detected of DEHP, beverage \#11, \#28 and \#30.

\section{Calculations}

The concentration of DEHP detected was calculated by taking the DEHP signal intensity difference between the beverage sample and DEHP in the spiked sample. This difference indicated the relative intensity of $50.00 \mathrm{ppm}$ standard DEHP that was added to the spiked sample. The ratio of $50.00 \mathrm{ppm}$ to the difference in intensity was equivalent to the ratio of the concentration of DEHP in the diluted beverage sample to its signal intensity. (Appendix Table 7)

Based on the calculations (Appendix Sample Calculations), consumption of one full portion of the beverages \#11, \#28 and \#30 would not exceed the TDI limit per day. Beverage \#11 had $\sim 0.622 \mathrm{mg}$, beverage \#28 had $\sim 2.01 \mathrm{mg}$ and beverage \#30 had $1.47 \mathrm{mg}$ of DEHP in one full portion of the drink. These levels were below the TDI for a $70 \mathrm{~kg}$ person of $3.5 \mathrm{mg}$ per day.

A statistical analysis was not completed for this study because no DEHP was detected using the initial method for the first number of samples. Under time constraints, the other beverages could not be re-analysed using the new one method, that showed greater validity and reliability. The number of samples ran for the samples that showed DEHP detection were not large enough to have meaningful statistical analysis.

\section{Discussion}

Experiments have been performed to detect and quantify a number of phthalates known to have detrimental health effects on human such as endocrine disruption and malformation of reproductive organs, infertility and abnormal neurodevelopment (12). Following, the methods and results from a few studies completed on food and beverages will be compared to those from this study.

Previous studies indicated variations of sample preparation, screening, extraction and analysis procedures to detect and quantify different phthalates in environmental samples, including food $(3,14)$ and beverages (3) as well as consumer products made from polymers (30). As 
such, an exhaustive list may exist for methods developed and customized to different types of samples. However, the Agency for Toxic Substances and Disease Registry (ATSDR) reported several well-established methods as the standard method of analysis for DEHP in biological and environmental samples (30). According to the report by ATSDR, the standard methods to detect and quantify for DEHP in air, water, soil/sediments and food was usually by GC analysis (31).

Specifically relevant to this study, publications from Agilent Technologies (AT), the company that develops analytical instruments and performs tests and training, identified standard methods developed for rapid detection and quantification of DEHP using LC/MS/MS (liquid chromatography-mass spectrometry in tandems), GC/MS or LC/MS (liquid chromatography-mass spectrometry, also known as HPLC-MS) (32) due to their low detection limits, which the "lowest quantity of a substance that can be distinguished from the system noise absent of that substance (a blank value)" (40). Based on the tests performed, these instruments were reliable for rapid quantification of phthalates in food and beverages at concentrations lower than the mandated limits set by China and Taiwan, which was 1 part per million (ppm) (32). In fact, the lowest the LCMS-MS, GC-MS and LC-MS can detect is 20 ppb (parts per billion), $50 \mathrm{ppb}$ and $1 \mathrm{ppb}$, respectively (32). Agilent Technologies carried out tests on beverages via two methods, a traditional liquid-liquid extraction method used for GC analysis of phthalates in food in China using hexane and the Agilent Chem Elut solid phase extraction cartridge (32). The latter method is much easier, faster, less than 10 minutes, and costs less, with less exposure to phthalate contamination sources (32). The report noted that the LC-MS was used by Taiwan FDA for analysis of beverages, food powder, health care products and baked goods for DEHP using methanol and sonication for 20 minutes (32). According to a study by AT, 3 beverages were obtained from retail stores and tested using the GC methods developed by AT. The levels of DEHP for one of the beverages was $72.5 \mathrm{ppm}$, which was well above the set limits of $1 \mathrm{ppm}$ established in China and Taiwan (32). The other two samples showed no detection for DEHP. Several other samples were analyzed via the LCMS-MS method and the concentration of DEHP was detected to be $1.05 \mathrm{ppm}$, just slightly above the the $1 \mathrm{ppm}$ limit. Since the TDI sets the units in $\mathrm{mg} / \mathrm{kg} \mathrm{bw} / \mathrm{day}$, it is not feasible to make a comparison to the concentration in ppm, unless the volume of the drink is provided, which, in this case was not. Therefore, the concentration of phthalate, reported in ppm, was compared to the concentration limit of $1 \mathrm{ppm}$ set by Taiwan and China instead of to the TDI.

Another research study was performed to quantify the levels of a different phthalate, dicyclohexyl phthalate (DCHP), in soy-based bubble tea via a simple dilution using $1 \mathrm{M}$ acetic acid to make a 1:5 mixture, then a further dilution in methanol to make a 1:9 mixture. Detection and quantification analysis was performed using ESI-HPIMS. As much as 10 ppm of dicyclohexyl phthalate (DCHP) was detected in the soy-bubble tea filtrate (4). This concentration also greatly exceeds the $1 \mathrm{ppm}$ limit.

The current study was performed using a similar sample preparation procedure, with some slight differences, to the previous research study done on soy-based bubble tea (4). For both studies, the first part of the procedure was performed with a simple dilution using $1 \mathrm{M}$ acetic acid to make a 1:5 mixture (4). The previous study, however, involved further dilution in methanol to make a 
1:9 mixture and analysis using ESI-HPIMS (4) whereas this study did not involve further dilution and used GC-MS.

Although the chocolate drink from beverage \#28 brand showed detection of DEHP using this method, the results were not consistent between the replicates. One of the spiked samples of this drink showed no detection of DEHP, which was unusual. Upon speculation, the reason for this observation may be related to the nature of the drink itself; for example, the particular composition of the drink may have caused DEHP to precipitate out of solution instead of staying in solution. However, this speculation cannot be verified due to the time and funding restriction of this experiment. By observation, the chocolate drink was slightly different than the other types of drinks because the solution did not appear to be homogeneous, showed higher viscosity than water when shaken and formed lumps of solids when it was spiked with DEHP. As a result, a slight change in procedure was performed using methanol instead of $1 \mathrm{M}$ acetic acid for dilution. Methanol is more polar than acetic acid (34) and may be able to lower the polarity and viscosity of the sample to allow solvent extraction of DEHP according to the author's speculation. Certain phthalates have been reported to be insoluble in water but miscible in methanol and alcohol with ether (33). The method used by the previous research study have shown successful detection of phthalates in soy-based drinks where acetic acid was used to "crash out", precipitating from solution, the proteins before methanol was used to dilute the samples (4). In the current experiment, the three beverages that showed detection of DEHP showed consistent results when they were prepared using methanol instead of acetic acid.

Results for this study showed no detection for DEHP in 27 out of 30 samples purchased from

retail stores in Canada, including different types, such as fruit, yogurt, water, tea, milk tea, carbonated, grass jelly and coffee drinks. The samples, a chocolate drink, a protein drink, and an orange juice, with DEHP detected, had levels that were less than the TDI of $0.05 \mathrm{mg} / \mathrm{kg}$ bw/day $(12,17)$ if one entire portion of the drink was consumed by the average person weighing $70 \mathrm{~kg}$ in one day.

Calculations showed that the amount of DEHP in one full portion of beverage \#11, orange juice, beverage \#28, chocolate drink, and beverage \#30, protein drink, were $0.622 \mathrm{mg}, 2.01 \mathrm{mg}$ and $1.47 \mathrm{mg}$, respectively (Appendix Sample Calculations), which were lower than the calculated tolerable daily intake for a $70 \mathrm{~kg}$ person of $3.5 \mathrm{mg}$.

Contrary to the findings in other studies, which consistently showed higher phthalate concentration above the regulated limit $(4,32)$, this study found DEHP levels below the TDI for a $70 \mathrm{~kg}$ person. It is important to note that consumption of phthalate may come from other sources such as drinking water (6) or other types of exposures including migration from plastics into food $(1,8,10,13,14)$. As such, drinking up to one portion of the beverage \#28 or beverage \#30 drinks, however, will not guarantee that the total daily intake from all sources will be below the TDI. Phthalates have been considered for a long time as endocrine disruptors because exposure to them has been linked to development abnormalities and impair reproduction and development (12).

\section{Limitations}


Although this experiment followed one of the standard methods using GC-MS analysis, there were some limitations affecting the reliability of the results.

One limitation of this study was that the use of acetic acid may not be suitable for dilution and extraction of phthalates for all types of drinks. As noted in previous studies, different types of samples will call for different types of sample preparation, extraction and analytical procedures (30). Since this study involved many different types of drinks, including fruit, yogurt, water, tea, milk tea, carbonated, grass jelly, chocolate, protein and coffee drinks, there could be many differences in the composition of the drinks that may affect the analytical outcome between these drinks. These differences cannot be controlled for and may affect the reliability of the results. Results using acetic acid for dilution and extraction were not consistent for beverage \#28 chocolate drink, as a spiked sample showed no detection of phthalates. Other compounds that make up the composition of the samples also form part of the matrix that may cause the phthalate to precipitate or interfere with its ability to dissolve in the solvent added. Also the extra compounds may be a source of chemical interferences in the analysis and may skew the results. A report indicated that a liquid/liquid sample extraction will result in a higher contamination and background noise from chemical interferences in comparison to the Chem Elut sample extraction method (32).

Another limitation was there was not enough funding to analyze at least 30 replicates of each of the drinks, especially those that showed detection for DEHP. Since the drinks that showed detection for DEHP were found near the end of the experiment, there was not enough time to make more replicates that could improve the reliability of the method. If more funding was given, more replicates of the same drink from different bottles could have been analyzed. Since higher sample numbers, for example 30, could allow for a meaningful statistical analysis to be completed using a one-tail t-test on NCSS statistical software (24), this will help conclude on whether the results of DEHP detected were statistically significantly different than the TDI. With this study, a set of two results from each beverage will not be able to show any statistical significance because the results may be lower by chance or actually lower than the TDI on average. Because the method was changed near the end of the time period allotted for the project, there was not enough time to re-reanalyze those

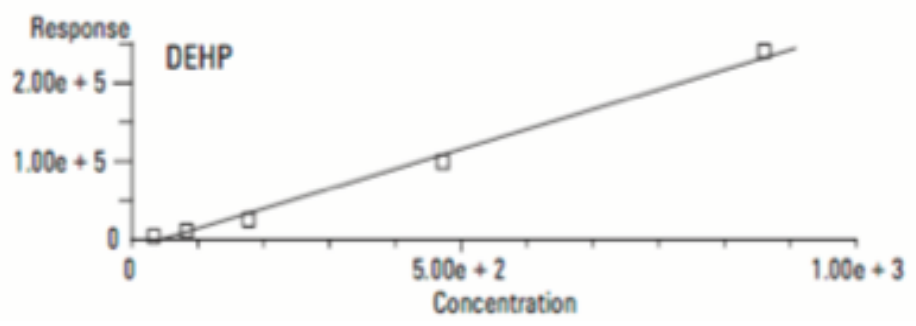

drinks, that were analyzed with acetic acid dilution, in methanol to verify the results from the first tests.

Also, calculations were based on the assumption that the matrix of two samples, the diluted beverage sample and the spiked sample, would produce noise due to chemical interference to the same extent. Although the sample matrix was the same for both, aliquots of these samples were taken separately; therefore, factors that may cause phthalates to increase or decrease in one sample may not do so to the same extent for the other. For this study, it was assumed that the matrix would interfere with DEHP to the same extent in both samples, the unspiked (beverage sample) and spiked samples.

For the purpose of calculating the DEHP level in the unspiked sample (beverage sample), the difference in the peak intensities between the 
spiked and unspiked sample was taken and then further inference of the DEHP level in the unspiked sample was calculated. However, this type of inference or extrapolation of data will not be as accurate as creating a linearity relationship, called a calibration curve (Figure 3) (26), of known standard concentrations and then extrapolating the concentration of DEHP using the peak intensity of the beverage sample (32). A calibration curve will allow for a correlation coefficient $\left(\mathrm{R}^{2}\right)$ to be calculated, which will indicate the degree of correlation between the standard control samples' concentrations. A greater linearity relationship is desired because it means there is consistency in the results as $R^{2}$ gets closer to 1 (32). For example, $\mathrm{R}^{2}$ of 0.998 means a good linearity relationship, which will result in a more accurate extrapolation of the DEHP level in the drink (32) from the calibration cure.

Figure 3: Sample Calibration Curve (32).

Furthermore, this experiment used a $70 \mathrm{~kg}$ person to convert the TDI from $\mathrm{mg} / \mathrm{kg}$ bw/day to $\mathrm{mg}$ /day for comparison purposes. Since the TDI takes into account the body weight, which varies between individuals, calculations based on a 70 $\mathrm{kg}$ body weight can only apply to certain individuals. For a person with a lower body weight, the TDI in $\mathrm{mg} /$ day will be lower as compared to a person with a higher body weight, where the TDI in $\mathrm{mg} /$ day will be higher. Therefore, the concluded implicated health effects for those who drink more than one can/bottle of the beverage will only be considered for a $70 \mathrm{~kg}$ body weight individual based on the results of this study.

Lastly, for beverage \#11, \#28 and beverage \#30 with DEHP detected, accounts of deliberation cannot be inferred from the results, without further follow-up.

\section{Recommendations}

Based on the results of this study, which showed promising results for DEHP levels in all of the drinks, there should be no major concern for DEHP in beverages completed in this study as levels were below the TDI for a $70 \mathrm{~kg}$ person drinking one full portion of the drink. However, since there were limitations in this experiment, as discussed, the reliability of the method was questionable. Therefore, it is recommended that further studies be done to address the limitations of this study and verify the outcomes.

As per the Food and Drug Regulation, pursuant to the Foods and Drugs Act, specialty food items such as imported drinks are required to have proper labelling on the can/bottle (21). Section B.01.012 (2) of the Regulation requires that the labels on the drinks must be in Canada's official languages, both English and French (21). By observation, some of the drinks did not meet this requirement. Also, section A.01.044 (1) of the Regulation mentioned that the imported product, if violates the Act or Regulations, may be sold in Canada if the violation is mitigated by giving an inspector the notice of the proposed importation and relabeling or modifying the product to enable its lawful sale in Canada (21). It is also a requirement to identify the place of business and the country on the label of all food products sold in Canada (35), which was not observed on some of the drinks. Therefore, it is recommended CFIA should consider inspecting retail stores for items that violate the Regulation and Act on a routine basis. It is also recommended that the findings for this study be referred to CFIA for further investigation.

The role of the government plays a huge role in preventing contaminated drinks from entering Canada. Currently, there are stringent laws against violations to the Food and Drugs Act 
(37) and Health Canada already has a list of permitted food additives (36). There is also a section in the Act on offences and punishment for a contravention, which mentioned a fine not exceeding $\$ 500$ or imprisonment for a term not exceeding 3 month or both (37). It is recommended that the government create requirements for the manufacturer to have laboratory tests completed for a list of harmful substances, which should include phthalate. Also more frequently, rather than annually (38), laboratory tests should be completed on the food products entering Canada for a list of harmful substances. Under the 2012-2013 executive summary report from the CFIA website, 120,000 tests were performed on many different types of food products (38) annually. It is suggested that the government reminds the public to check the food labels by means of the media. Public awareness is a key part in prevention strategies and helping them make informed choices during the next purchase of any food items.

\section{Future Research Suggestions}

For the future, it is suggested that much more funding should be granted for further studies that would allow for more replicates of the drinks to be analyzed and a wider variety of drinks. In future studies, methanol, or a better solvent should be used to extract the DEHP into solution. The calibration curve should be used to extrapolate the concentration of DEHP in the drinks to improve accuracy.

Further investigations into the detection of DEHP in beverage \#11 (from China), \#28 (from the U.S). (39), and \#30 (from Canada), should be carried out to find out the reason for the presence of DEHP in the drink. It is still unknown how DEHP is present in beverage \#11, \#28 and \#30 until more investigation is done. This may involve making phone calls and finding out the exact location, which was not provided on the can, of the manufacturer of the product.

Beverage \#28 contains more DEHP than beverage \#30 and \#11 in this study. Perhaps a study could be done to find out whether the amount in one drink is statistically different than the other.

Other suggestions include analyzing 30 drinks from only one country, or two countries, such as, Canada and USA, to make a comparison.

\section{Conclusion}

Multiple literature supported through their studies that consuming drinks contaminated with phthalates would far exceed the daily limits set out by the established safety guidelines for an average weighted person (15). However, this current study did not indicate this for the drinks that were analyzed.

The results from the study indicated no detection for DEHP in 27 of the 30 drinks analyzed. The three drinks in which DEHP was detected had less than the TDI limit of $0.05 \mathrm{mg} / \mathrm{kg} /$ day for a $70 \mathrm{~kg}$ person drinking one full portion of the drink (volume will vary). However, exceeding one can could have health implications on the individual as the DEHP level would exceed the TDI limit of $0.05 \mathrm{mg} / \mathrm{kg} \mathrm{bw} /$ day for a $70 \mathrm{~kg}$ person.

No statistical analysis was completed on this project because there was no DEHP detected in any of the drinks up until the very last few drinks using the new method, when the author did not have enough time to analyze more replicates of those samples. Without more replicates, for example, 30 replicates of each drink, a statistical 
analysis would not be feasible to conclude on the statistical significance of the results (25).

In conclusion, beverages from the countries including Taiwan, Korea, Japan, Singapore, China, India, Pakistan, Philippines, Thailand, USA, Poland and Canada showed DEHP levels that were lower than the TDI of $0.05 \mathrm{mg} / \mathrm{kg}$ bw/day for a $70 \mathrm{~kg}$ body weight if one full portion is consumed within a day. This is a positive finding, although certain limitations of the study must also be considered.

\section{Acknowledgements}

Thank you too all the teachers and supervisors who had helped with this project.

\section{Competing Interest}

The authors declare that they have no competing interests.

\section{References}

1. Goldman L. Food Contaminants and Children: Cause for Concern. Reviews in Food and Nutrition Toxicity [Internet]. 2005 [cited 18 October 2015];3. Available from:

https://books.google.ca/books?hl=en\&lr=\&i $\mathrm{d}=\mathrm{yrAybB} 2 \mathrm{UGE} 4 \mathrm{C} \&$ oi $=$ fnd\&pg=PA221\& $\mathrm{dq}=$ food + contaminants + and + children: + cau $\mathrm{se}+$ for + concern\&ots $=\mathrm{x} 9 \mathrm{wqPi}-$

9zJ\&sig=Wy4-73jRRa3SOeOuWLjb6RMZfY\#v=onepage $\& \mathrm{q}=$ food $\% 20$ contaminants $\% 20$ and $\% 20$ chil dren $\% 3 \mathrm{~A} \% 20$ cause $\% 20$ for $\% 20$ concern $\& \mathrm{f}=$ false

2. Fierens T, Serves K, Holderbeke M, Geerts L, Henauw S, Sioen I et al. Analysis of Phthalates in Food Products and Packaging
Materials Cold on the Belgian Market. Food and Chemical Toxicology [Internet]. 2012 [cited 19 October 2015];50(7):25752583. Available from:

http://www.elsevier.com/locate/foodchemto $\mathrm{x}$

3. Midey A, Camacho A, Sampathkumaran J, Krueger C, Osgood M, Wu C. Highperformance ion mobility spectrometry with direct electrospray ionization (ESIHPIMS) for the detection of additives and contaminants in food. Analytica Chimica Acta. 2013; 804:197-206.

4. Midey A, Sampathkumaran J, Krueger C, Osgood M, Wu J, Wu C. ESI-HPIMS for Rapid Screening of Food Contaminants. Excellims Innovation for Excellence in Detection Technology [Internet]. 2010 [cited 20 October 2015]. Available from: http://www.excellims.com

5. Fankhauser-Noti A, Grob K. Blank Problems in Trace Analysis of Diethylhexyl and Dibutyl Phthalate: Investigation of the sources, tips and Tricks. Analytica Chimica Acta [Internet]. 2006 [cited 15 October 2015];582(2007):353-360. Available from: http://www.sciencedirect.com

6. Considerations on Ultra-Trace Analysis of Phthalates in Drinking Water. Water Research [Internet]. 2006 [cited 14 October 2015];40(2006):2572-2582. Available from: http://www.elsevier.com/locate/watrea

7. Kang J, Chu S, Wu Z, Chou S, Tsai S, Chiu W. Crisis Management turns Taiwan's Plasticizer Nightmare into Progressive Policy. Journal of the Formosan Medical Association [Internet]. 2012 [cited 14 October 2015];111(2012):409-411. Available from: http:/www.jfma- 
online.com/article/S0929-6646(12)00361$0 /$ abstract

8. Guo Z, Wang S, Wang M, Zhang H, Gai P, Dean J. Development and Application of a Method for Analysis of Phthalates in Ham Sausages by Solid-Phase Extraction and Gas Chromatography-Mass Spectrometry. Meat Science [Internet]. 2010 [cited 15 October 2015]; 84:484-490. Available from:

http://www.elsevier.com/locate/meatsci

9. Li X, Fang E, Scheibye-Knudsen M, Cui H, Qiu L, Li J et al. Di-(2-ethylhexyl) Phthalate Inhibits DNA Replication Leading to HyperPARylation, SIRT1 Attenuation, and Mitochondrial Dysfunction in the Testis. Scientific Reports [Internet]. 2014 [cited 16 October 2015]; 4:7-9. Available from: http://www.nature.com/scientificreports

10. Fierens T, Vanermen G, Holderbeke N, Henauw S, Sioen I. Effect of Cooking at Home on the Levels Eight Phthalates in Foods. Food and Chemical Toxicology [Internet]. 2012 [cited 20 October 2015]; 50:4428-4435. Available from: http://www.elsevier.com/locate/foodchemto $\mathrm{X}$

11. Yen T, Lin-Tan D, Lin J. Food Safety Involving Ingestion of Foods and Beverages Prepared with PhthalatePlasticizer- Containing Clouding Agents. Journal of Formosan Medical Association [Internet]. 2011 [cited 15 October 2015]; 110:671-684. Available from: http://www.jfma-online.com

12. Wu M, Wu C, Chen B, Chen E, Chen Y, Shiea J et al. Intake of Phthalate-Tainted Foods Alters Thyroid Functions in Taiwanese Children. PLOS ONE [Internet].
2013 [cited 17 October 2015];8(1):1-9. Available from: http://www.plosone.org

13. Fasano E, Bono-Blay F, Cirillo T, Montuorri P, Lacorte S. Migration of Phthalates, Alkylphenols, Bisphenol A and Di(2ethylhexyl) adipate from Food Packaging. Food Control [Internet]. 2012 [cited 18 October 2015];27(1):132-138. Available from: http://www.elsevier.com/locate/foodcont

14. Self R, Wu W. Rapid Qualitative Analysis of Phthalates Added to Food and Nutraceutical Products by Direct Analysis in Real time/Orbitrap Mass Spectrometry. Food Control [Internet]. 2012 [cited 20 October 2015];25(1):13-16. Available from: http://www.elsevier.com/locate/foodcont

15. Yang J, Hauser R, Goldman R. Taiwan Food Scandal: The Illegal use of Phthalates as a Clouding Agent and their Contribution to Maternal Exposure. Food and Chemical Toxicology [Internet]. 2012 [cited 18 October 2015]; 58:362-368. Available from:

http://www.elsevier.com/locate/foodchemto $\mathrm{X}$

16. Dong T. The Knowledge, Attitude, and Practice of Consumers Towards Food Safety Issues: A Review of Taiwan. International Journal of Research Studies in Management. 2015;4(2):13-22.

17. Wu M, Wu C, Wu J, Chen B, Chen E, Chao $\mathrm{M}$ et al. The Public Health Threat of Phthalate-Tainted Foodstuffs in Taiwan: The Policies the Government Implemented and the Lessons We Learned. Environmental International [Internet]. 2012 [cited 19 October 2015]; 44:75-79. Available from: http://www.elsevier.com/locate/envint 
18. Inspection.gc.ca. Section E - Guide to Importing Food Products Commercially Food - Canadian Food Inspection Agency [Internet]. 2015 [cited 18 October 2015]. Available from: http://www.inspection.gc.ca/food/imports/c ommercial-importers/importing-foodproducts/eng/1376515896184/1376515983 781 ? chap $=6 \# \mathrm{~s} 15 \mathrm{c} 6$

19. Healthline. What Is the Nutritional Value of Boba? [Internet]. 2015 [cited 20 October 2015]. Available from: http://www.healthline.com/health/foodnutrition/nutritional-value-of-boba\#3

20. Justice Laws Website. Processed Products Regulations [Internet]. 2015 [cited 17 October 2015]. Available from: http://lawslois.justice.gc.ca/eng/regulations/C.R.C.,_c. 291/page-1.html

21. Laws-lois.justice.gc.ca. Food and Drug Regulations [Internet]. 2015 [cited 20 October 2015]. Available from: http://lawslois.justice.gc.ca/eng/regulations/c.r.c.,_c._ 870/page-1.html

22. Cs.cmu.edu. Mass Spec Calibration Compounds - General Index [Internet]. 2015 [cited 11 November 2015]. Available from: http://www.cs.cmu.edu/ sensingsensors/readings/MS_Calibration_Spectra.h tml

23. Sigmaaldrich.com. Bis(2-ethylhexyl) phthalate solution $5000 \hat{\mathrm{A}} \hat{\mathrm{I}} 1 / \mathrm{g} / \mathrm{mL}$ in methanol, analytical standard $\mid$ SigmaAldrich [Internet]. 2015 [cited 9 November 2015]. Available from: http://www.sigmaaldrich.com/catalog/prod uct/supelco/40064?lang=en\&region=US

24. NCSS Statistical Software. NCSS; 2010.

25. Heacock H. Research Methods: Descriptive
Statistics. Presentation presented at; 2015; British Columbia Institute of Technology.

26. Martin B. An Introduction to Standards and Quality Control for the Laboratory [Internet]. Hach.com. 2002 [cited 8 November 2015]. Available from: http://www.hach.com/assetget.download.jsa?id=7654714981

27. Barden D. Phthalates in toys - A continuing problem [Internet]. Markes.com. 2016 [cited 2 May 2016]. Available from: http://www.markes.com/blog/Phthalatesin-toys-A-continuing-problem.aspx

28. Miley A, Sampathkumaran J, Krueger C, Osgood M, Wu J, Wu C. ESI-HPIMS for Rapid Screening of Food Contaminants. Excellims Innovation for Excellence in Detection Technology [Internet]. 2010 [cited 20 October 2015]. Available from: http://www.excellims.com

29. Tahmasebi E, Masoomi M, Yamini Y, Morsali A. Application of a Zn(ii) based metal-organic framework as an efficient solid-phase extraction sorbent for preconcentration of plasticizer compounds. RSC Adv. 2016;6(46):40211-40218.

30. Analytical Methods [Internet]. 2016. Available from: http://www.atsdr.cdc.gov/toxprofiles/tp9c7.pdf

31. Registry A. Agency for Toxic Substances and Disease Registry [Internet]. Atsdr.cdc.gov. 2016 [cited 4 March 2016]. Available from: http://www.atsdr.cdc.gov

32. Agilent Technologies, Inc. Rapid, Sensitive, and Robust Detection of Phthalates in Food Using GC/MS or LC/MS [Internet]. 
US; 2012 p. 1-13. Available from:

https://www.agilent.com/cs/library/applicat ions/5990-9510EN.pdf

33. Reference Tables: Description and Solubility - P [Internet]. Pharmacopeia.cn. 2016 [cited 6 March 2016]. Available from: http://www.pharmacopeia.cn/v29240/usp2 9nf24s0_alpha-2-25.html

34. McMurry J. Organic Chemistry. 6th ed. Belmont: Thomson Brooks/Cole; 2004.

35. Labelling Requirements Checklist - Food Canadian Food Inspection Agency [Internet]. Inspection.gc.ca. 2014 [cited 6 March 2016]. Available from: http://www.inspection.gc.ca/food/labelling /food-labelling-for-industry/labellingrequirementschecklist/eng/1393275252175/1393275314 581

36. Lists of Permitted Food Additives - Health Canada [Internet]. Hc-sc.gc.ca. 2016 [cited 6 March 2016]. Available from: http://www.hc-sc.gc.ca/fnan/securit/addit/list/index-eng.php

37. Food and Drugs Act [Internet]. Lawslois.justice.gc.ca. 2016 [cited 6 March 2016]. Available from: http://lawslois.justice.gc.ca/eng/acts/F-27/page6.html\#h-19
38. National Chemical Residue Monitoring Program 2012-2013 Report - Food Canadian Food Inspection Agency [Internet]. Inspection.gc.ca. 2014 [cited 6 March 2016]. Available from: http://www.inspection.gc.ca/food/chemical -residues-microbiology/chemicalresidues/ncrmpreport/eng/1415838181260/141583826589 6

39. Dr Pepper Snapple Group [Internet]. DrPepperSnappleGroup.com. 2016 [cited 6 March 2016]. Available from: http://www.drpeppersnapplegroup.com

40. Agilent Technologies, Inc. Signal, Noise, and Detection Limits in Mass Spectrometry [Internet]. US; 2011 p. 1-7. Available from https://www.agilent.com/cs/library/technic aloverviews/Public/5990-7651EN.pdf

41. Guidance on Selected Default Values to be Used by The EFSA Scientific Committee, Scientific Panels and Units in the Absence of Actual Measured Data1 [Internet]. European Food Safety Authority. 2016 [cited 28 April 2016]. Available from: http://www.efsa.europa.eu/sites/default/file s/scientific_output/files/main_documents/2 579.pdf 


\section{Appendix}

Table 1: Results for Beverage Samples Analyzed (and their Duplicates) using 1:5 Ratio of Beverage and Acetic Acid

\begin{tabular}{|c|c|c|c|}
\hline Beverage \# & Type & $\begin{array}{c}\text { Country } \\
\text { Made }\end{array}$ & DEHP Detection \\
\hline 1 & Strawberry Bubble Tea & Taiwan & Absence \\
\hline 2 & Grass Jelly & Taiwan & Absence \\
\hline 3 & Milk Coffee & Taiwan & Absence \\
\hline 4 & Coconut Milk & Taiwan & Absence \\
\hline 5 & Aloe Vera & Korea & Absence \\
\hline 6 & Milk Tea & Japan & Absence \\
\hline 7 & Grass Jelly & Taiwan & Absence \\
\hline 8 & Honey White Gourd Milk & Taiwan & Absence \\
\hline 9 & Grass Jelly & Singapore & Absence \\
\hline 10 & Fresh Lemon Juice with Honey & China & Absence \\
\hline 11 & Orange Juice & China & Absence \\
\hline
\end{tabular}




\begin{tabular}{|c|c|c|c|}
\hline Beverage \# & Type & $\begin{array}{c}\text { Country } \\
\text { Made }\end{array}$ & DEHP Detection \\
\hline 12 & Tea & China & Absence \\
\hline 13 & Salt Water & Unknown & Absence \\
\hline 14 & Milk Tea (all characters) & China & Absence \\
\hline 15 & Guava & Taiwan & Absence \\
\hline 16 & Tea & Unknown & Absence \\
\hline 17 & Mango & Unknown & Absence \\
\hline 18 & Litchi & India & Absence \\
\hline 19 & Milk & Taiwan & Absence \\
\hline 20 & Carbonated Fruit Flavour & Pakistan & Absence \\
\hline 21 & Tea & Taiwan & Absence \\
\hline 22 & Fruit Flavour & Unknown & Absence \\
\hline 23 & Orange Juice & Unknown & Absence \\
\hline 24 & Yogurt & China & Absence \\
\hline 25 & Grass Jelly & China & Absence \\
\hline 26 & Guyabano Nectar & Philippines & Absence \\
\hline 27 & Young Coconut Juice with Pulp & Thailand & Absence \\
\hline 28 & Chocolate & USA & Presence \\
\hline
\end{tabular}

Table 2: Results for Randomly Selected Beverage Samples versus Spiked Samples using 1:5 Ratio of Beverage and Acetic Acid

\begin{tabular}{|c|c|c|c|c|}
\hline Sample \# & Sample Type & Type & Country Made & DEHP Detection \\
\hline $14 \mathrm{a}$ & Beverage Sample & Milk Tea & Japan & Absence \\
\hline $14 \mathrm{~b}$ & Spiked Sample & Milk Tea & Japan & Presence \\
\hline \multicolumn{5}{|l}{} \\
\hline $18 \mathrm{a}$ & Beverage Sample & Litchi & India & Absence \\
\hline $18 \mathrm{~b}$ & Spiked Sample & Litchi & India & Presence \\
\hline \multicolumn{5}{|l}{} \\
\hline $28 \mathrm{a}$ & Beverage Sample & Chocolate & USA & Presence \\
\hline $28 \mathrm{~b}$ & Beverage Sample & Chocolate & USA & Presence \\
\hline $28 \mathrm{c}$ & Beverage Sample & Chocolate & USA & Presence \\
\hline $28 \mathrm{~d}$ & Beverage Sample & Chocolate & USA & Presence \\
\hline $28 \mathrm{e}$ & Spiked Sample & Chocolate & USA & Absence \\
\hline
\end{tabular}

Table 3: Results for Samples using a 1:1 Ratio of Beverage and Acetic Acid

\begin{tabular}{|c|c|c|c|c|}
\hline Sample \# & Sample Type & Type & Country Made & DEHP Detection \\
\hline $28 \mathrm{f}$ & Beverage Sample & Chocolate & USA & Presence \\
\hline $28 \mathrm{~g}$ & Beverage Sample & Chocolate & USA & Absence \\
\hline
\end{tabular}




\begin{tabular}{|c|c|c|c|c|}
\hline Sample \# & Sample Type & Type & Country Made & DEHP Detection \\
\hline $28 \mathrm{~h}$ & Beverage Sample & Chocolate & USA & Absence \\
\hline $28 \mathrm{i}$ & Spiked Sample & Chocolate & USA & Presence \\
\hline
\end{tabular}

Table 4: Results for Samples using a 1:1 Ratio of Beverage and Methanol

\begin{tabular}{|c|c|c|c|c|c|}
\hline Sample \# & Sample Type & Type & Country Made & DEHP Detection & Signal Intensity \\
\hline $28 \mathrm{j}$ & Beverage Sample & Chocolate & USA & Presence & 6186 \\
\hline $28 \mathrm{k}$ & Spiked Sample & Chocolate & USA & Presence & 172132 \\
\hline 281 & Beverage Sample & Chocolate & USA & Presence & 4735 \\
\hline $28 \mathrm{~m}$ & Spiked Sample & Chocolate & USA & Presence & 198121 \\
\hline
\end{tabular}

Table 5: Results for Samples using a 1:1 Ratio of Beverage and Methanol

\begin{tabular}{|c|c|c|c|c|c|}
\hline Sample \# & Sample Type & Type & Country Made & DEHP Detection & Signal Intensity \\
\hline 30a & Beverage Sample & Protein & Canada & Presence & 13030 \\
\hline 30b & Spiked Sample & Protein & Canada & Presence & 559391 \\
\hline 30c & Beverage Sample & Protein & Canada & Presence & 13093 \\
\hline 30d & Spiked Sample & Protein & Canada & Presence & 520173 \\
\hline \multicolumn{7}{|l|}{} \\
\hline $11 \mathrm{a}$ & Beverage Sample & Orange Juice & China & Presence & 8312 \\
\hline $11 \mathrm{~b}$ & Spiked Sample & Orange Juice & China & Presence & 1700085 \\
\hline $11 \mathrm{c}$ & Beverage Sample & Orange Juice & China & Presence & 14414 \\
\hline $11 \mathrm{~d}$ & Spiked Sample & Orange Juice & China & Presence & 1635369 \\
\hline
\end{tabular}

Table 6: Summary of Results for Beverage Samples Analyzed using 1:1 Ratio of Beverage and Methanol

\begin{tabular}{|c|c|c|c|}
\hline Beverage \# & Type & Country Made & DEHP Detection \\
\hline 28 & Chocolate & USA & Presence \\
\hline 29 & Uroda & Poland & Absence \\
\hline 30 & Protein & Canada & Presence \\
\hline
\end{tabular}

Table 7: Calculated Concentrations of DEHP for Beverage Samples \#28, \#30 and \#11.

\begin{tabular}{|c|c|c|c|c|}
\hline Sample \# & Sample Type & $\begin{array}{c}\text { DEHP } \\
\text { Detection }\end{array}$ & DEHP (ppm) & $\begin{array}{c}\text { Average DEHP } \\
(\mathbf{p p m})\end{array}$ \\
\hline $28 \mathrm{j}$ & Beverage Sample & Presence & 1.864 & 1.544 \\
\hline 281 & Beverage Sample & Presence & 1.224 & \multirow{2}{*}{1.242} \\
\hline \multicolumn{5}{|l|}{} \\
\cline { 1 - 3 } 30a & Beverage Sample & Presence & 1.192 & \\
\hline
\end{tabular}




\begin{tabular}{|c|c|c|c|c|}
\hline Sample \# & Sample Type & $\begin{array}{c}\text { DEHP } \\
\text { Detection }\end{array}$ & DEHP (ppm) & $\begin{array}{c}\text { Average DEHP } \\
(\mathrm{ppm})\end{array}$ \\
\hline$\overline{11 a}$ & Beverage Sample & Presence & 0.246 & \multirow{2}{*}{0.346} \\
\hline $11 \mathrm{c}$ & Beverage Sample & Presence & 0.445 & \\
\hline
\end{tabular}

\section{Sample Calculations:}

Sample calculations for sample $28 \mathrm{j}$ using signal intensity from sample $28 \mathrm{k}$ (spiked sample):

$$
\begin{gathered}
172132-6186=165946 \\
\frac{50.00 p p m}{165946}=\frac{x}{6186} \\
x=50.00 p p m * \frac{6186}{165946} \\
x \sim 1.864 p p m
\end{gathered}
$$

$x$ is the DEHP concentration in the diluted sample. Results for the average DEHP concentrations in the beverage \#28, \#30 and \#11 were calculated and tabulated in Appendix Table 7.

DEHP levels (mg) in original beverage \#28 (325mL portion) can be calculated as follows:

$$
\begin{gathered}
1.544 \mathrm{ppm} * 0.002 \mathrm{~L} * \frac{2 \mathrm{~mL}}{1 \mathrm{~mL}}=0.006276 \mathrm{mg} \text { in } 1 \mathrm{~mL} \text { of the original sample } \\
\frac{0.006276 \mathrm{mg}}{m L} * 325 \mathrm{~mL}=2.0072 \sim 2.01 \mathrm{mg}
\end{gathered}
$$

DEHP levels (mg) in original beverage \#30 (296mL portion) can be calculated as follows:

$$
\begin{gathered}
1.242 \mathrm{ppm} * 0.002 \mathrm{~L} * \frac{2 \mathrm{~mL}}{1 \mathrm{~mL}}=0.0049669 \mathrm{mg} \text { in } 1 \mathrm{~mL} \text { of the original sample } \\
\frac{0.0049669 \mathrm{mg}}{\mathrm{mL}} * 296 \mathrm{~mL}=1.4702 \sim 1.47 \mathrm{mg}
\end{gathered}
$$

DEHP levels (mg) in original beverage \#11 (450mL portion) can be calculated as follows:

$$
\begin{gathered}
0.3455 \mathrm{ppm} * 0.002 \mathrm{~L} * \frac{2 \mathrm{~mL}}{1 \mathrm{~mL}}=0.001382 \mathrm{mg} \text { in } 1 \mathrm{~mL} \text { of the original sample } \\
\frac{0.001382 \mathrm{mg}}{\mathrm{mL}} * 450 \mathrm{~mL}=\sim 0.622 \mathrm{mg}
\end{gathered}
$$

For a $70 \mathrm{~kg}$ person, the tolerable intake per day can be calculated as follows: 
$\frac{0.05 m g}{k g \frac{b w}{d a y}} * 70 \mathrm{~kg}=3.5 \mathrm{mg} / \mathrm{day}$ 
